Research article

\title{
Genetic polymorphisms in the cyclooxygenase-2 gene, use of nonsteroidal anti-inflammatory drugs, and breast cancer risk
}

\author{
Jing Shen ${ }^{1}$, Marilie D Gammon², Mary Beth Terry ${ }^{3}$, Susan L Teitelbaum ${ }^{4}$, Alfred I Neugut ${ }^{3}$ and \\ Regina M Santella ${ }^{1}$
}

\author{
1Department of Environmental Health Sciences, Mailman School of Public Health, Columbia University, 630 West 168th Street, New York, New York \\ 10032, USA \\ 2Department of Epidemiology, School of Public Health, University of North Carolina, CB\#7435 McGavern-Greenberg Hall, Chapel Hill, North \\ Carolina 27599, USA \\ ${ }^{3}$ Department of Epidemiology, Mailman School of Public Health, Columbia University, 722 West 168th Street, New York, New York 10032 , USA \\ ${ }^{4}$ Department of Community and Preventive Medicine, Mt. Sinai School of Medicine, One Gustave Levy Place, Box 1043, New York, New York 10029, \\ USA
}

Corresponding author: Jing Shen, js2182@columbia.edu

Revisions requested: 2 Nov 2006 Revisions received: 29 Nov 2006 Accepted: 20 Dec 2006 Published: 20 Dec 2006

Breast Cancer Research 2006, 8:R71 (doi:10.1186/bcr1629)

This article is online at: http://breast-cancer-research.com/content/8/6/R71

(c) 2006 Shen et al.; licensee BioMed Central Ltd

This is an open access article distributed under the terms of the Creative Commons Attribution License (http://creativecommons.org/licenses/by/2.0), which permits unrestricted use, distribution, and reproduction in any medium, provided the original work is properly cited.

\begin{abstract}
Introduction The association between use of nonsteroidal antiinflammatory drugs (NSAIDs) and breast cancer risk remains unclear. Inconsistencies in previously reported findings may be partly due to differences in expression of cyclooxygenase (COX)-2. We hypothesized that genetic polymorphisms (COX2.926, COX-2 .5209, and COX-2 .8473) may reduce overall breast cancer risk or risk for subtypes of breast cancer by modulating the inflammatory response and may interact with aspirin or any NSAID use.
\end{abstract}

Methods We conducted a population-based, case-control study in which we genotyped 1,067 breast cancer cases and 1,110 control individuals included in the Long Island Breast Cancer Study Project.

Results No major effects of the three COX-2 variant alleles on breast cancer risk were found. A total of eight distinct haplotypes and 18 diplotypes were observed in the population. Overall, no significant associations between COX-2 haplotypes/diplotypes and breast cancer risk were observed. Among women who used aspirin or any NSAID there was little evidence for an interaction with the at-risk COX-2 genotypes, with one exception. Among women with hormone receptor positive breast cancer, the reduced risk for any NSAID use was only evident among those who had at least one variant $\mathrm{C}$ allele of COX-2 .8473 (odds ratio $=0.7,95 \%$ confidence interval $=$ 0.5 to $1.0 ; P$ for the interaction $=0.02$ ). There was no corresponding interaction for aspirin use, possibly because of limited power.

Conclusion These data provide modest evidence that the $\mathrm{C}$ allele of COX-2 .8473 may interact with NSAIDs to reduce risk for hormone receptor positive breast cancer.

\section{Introduction}

In recent years, several relatively large studies have examined the association between nonsteroidal anti-inflammatory drugs (NSAIDs) and breast cancer. A meta-analysis of 14 studies (six prospective studies and eight case-control studies) [1] demonstrated a decrease of $20 \%$ in the risk for breast cancer among NSAID users. Harris and coworkers [2] observed an inverse relationship between incidence of breast cancer and intake of NSAIDs in a prospective cohort study, with an approximately $40 \%$ decreased risk for breast cancer in regular aspirin users. More recent studies [3,4], including our previous analyses from the Long Island Breast Cancer Study Project [5], demonstrated that use of aspirin (the most commonly used NSAID) is associated with a significant reduction in risk for breast cancer, especially for hormone receptor positive tumors. However, data from several recent cohort studies $[6,7]$ have been less consistent.

$\mathrm{Cl}=$ confidence interval; $\mathrm{COX}=$ cyclooxygenase; $\mathrm{ER}=$ estrogen receptor; $\mathrm{NSAID}=$ nonsteroidal anti-inflammatory drug; $\mathrm{OR}=$ odds ratio; $\mathrm{PG}=$ prostaglandin; $\mathrm{PR}=$ progesterone receptor; $\mathrm{SNP}=$ single nucleotide polymorphism; UTR $=$ untranslated region. 
The anticancer activity of NSAIDs is believed to be due to inhibition of cyclooxygenase (COX)-2, which is over-expressed in many types of cancer, including breast cancer, and plays a major role in tumorigenesis [8,9]. COX-2 encodes one of two COX enzymes that catalyze the synthesis of prostaglandins (PGs) from the dietary fatty acid arachidonic acid [10]. Increased COX-2 levels are associated with increased angiogenesis, increased estrogen synthesis, and reduced apoptosis, all of which may stimulate tumor growth [7]. In breast cancer PGs, particularly $\mathrm{PGE}_{2}$, have an organ-site-specific effect of increasing the levels of aromatase, thereby increasing estrogen and progesterone synthesis [10-12]. COX-2 expression has been reported in a significant proportion of preinvasive and invasive breast cancers [10,13], and different frequencies of COX-2 over-expression have been observed in subgroups of breast cancer patients by hormone receptor status (estrogen receptor [ER] and progesterone receptor [PR]). More frequent elevation in COX-2 expression was noted in ER/PR-negative breast cancer [14]. COX-2 expression also had a different impact on prognosis in subgroups of tumors. Elevated expression of COX-2 was associated with poor survival in ER-positive or PR-positive tumors $(P<0.002)$ but not in ER/PR-negative ones [14]. Therefore, it is biologically plausible that the protective effect of NSAIDs comes, at least in part, from limiting either the amount or activity of COX-2 present in the cell, both of which are partly determined by specific polymorphisms [15-18].

The previous inconsistent findings on the association between NSAIDs and breast cancer risk might be explained by interindividual differences in COX-2 gene expression or be limited to certain subtypes of breast cancer. Thus, we hypothesized that potential functional genetic polymorphisms (variant alleles or haplotypes/diplotypes) in COX-2 that result in altered expression and/or activity of the protein may modulate the inflammatory response, modifying overall breast cancer risk or risk for subtypes of breast cancer. Single nucleotide polymorphisms (SNPs) in the promoter and 3'-untranslated region (UTR) of COX-2 were previously reported to modulate the risks for prostate, colorectal, esophageal, gastric, bladder, biliary tract, and non-small-cell lung cancer [17,19-31]. A few previous reports showed that the COX-2 .926 G $\rightarrow$ C polymorphism examined here can result in higher COX-2 expression and lead to an approximate $30 \%$ reduction in promoter activity in vitro $[15,18]$. No functional studies of other COX-2 polymorphisms potentially associated with cancer risks have been reported. Little is known regarding COX-2 polymorphism and breast cancer risk and its potential interactions with aspirin and NSAID use [32-35].

\section{Materials and methods Study population}

The study population of the Long Island Breast Cancer Study Project has been described in detail previously [36]. In brief, cases were adult female residents of Nassau and Suffolk counties on Long Island, New York, who were of any age or race, spoke English, and were newly diagnosed with in situ or invasive breast cancer between 1 August 1996 and 31 July 1997. Control individuals were frequency matched to the expected age distribution of the cases and were identified through random digit dialing for women aged under 65 years and through the Center for Medicare and Medicaid Services rosters for women aged 65 years and older. Eligible control individuals were women who spoke English and who resided in the same Long Island counties as the cases, but who had no personal history of breast cancer. The study was conducted with approval from participating institutional review boards, and in accordance with an assurance filed with and approved by the US Department of Health and Human Services.

Interview response rates among eligible cases and controls were $82.1 \%(n=1,508)$ and $62.8 \%(n=1,556)$, respectively. Of those who completed the 100-minute main questionnaire, $73.1 \%$ of cases $(1,102)$ and $73.3 \%$ of controls $(1,141)$ donated a blood sample [36]. As previously reported, an increase in breast cancer among women on Long Island was found to be associated with lower parity, late age at first birth, little or no breastfeeding, a family history of breast cancer, and increasing income and education [36]. Results were similar when the analyses were restricted to respondents who donated blood [36] or to those with DNA available for these analyses (data not shown). Factors that were found to be associated with decreased likelihood that a respondent would donate blood included increasing age, past smoking status, ever consuming alcohol, ever breastfeeding, ever using hormone replacement therapy, ever using oral contraceptives, and ever having had a mammogram. Case-control status was not a predictor of blood donation [36].

\section{Selection of single nucleotide polymorphisms}

The human COX-2 gene contains 10 exons and spans 8.3 kilobases [37]. We collected data on COX-2 polymorphisms from publicly available databases, such as dbSNP [38], UCSC Genome Bioinformatics [39], and GeneCards [40]. A total of 124 SNPs in COX-2 were identified and the studied SNPs chosen according to the following criteria: (a) a minor allele frequency of $5 \%$ or greater in Caucasians, according to literature data; and (b) more than $80 \%$ homology between human and rat/mouse genome, or (c) previous laboratory evidence indicating a significant functional effect, or (d) previous epidemiologic findings indicating associations with cancer susceptibility. Finally, three SNPs were selected and genotyped for the present study: COX-2 .926 G $\rightarrow \mathrm{C}$ (promoter region, rs20417), which satisfies all four criteria; and COX-2 $.5209 \mathrm{G} \rightarrow \mathrm{T}$ (intron 5, rs20432) and COX-2 .8473 $\mathrm{C} \rightarrow \mathrm{T}$ (exon 10, 3'-UTR, rs5275), both of which satisfy three of the four criteria (specifically, criteria a, b, and d). 


\section{Genotyping}

Genomic DNA was extracted [41] by standard RNase/proteinase $\mathrm{K}$ and phenol/chloroform treatment and genotyped by a fluorescence polarization method, using a commercial AcycloPrime $^{\mathrm{TM}}$-FP SNP Detection Kit obtained from PerkinElmer Life Sciences (Boston, MA, USA) [42]. The forward and reverse primers were designed according to the human $\mathrm{COX}-2$ gene sequence (GeneBank accession number D28235.1) and were (respectively) as follows: 5'-CAT TTA GCG TCC CTG CAA AT-3' and 5'-TAC CTT CAC CCC CTC CTT GT-3' for COX-2 .926; 5'-CAT GAT TAT GCC GCT TTC AA-3' and 5'TCC ACC AAA GCT ACA AAC TGA-3' for COX-2 .5209; and 5'-TTC CAA TGC ATC TTC CAT GA-3' and 5'-TCA AAC AAG CTT TTA CAG GTG A-3' for COX-2 .8473. The sequences of TDI (Template-directed Dye-terminator Incorporation) probes were designed using Primer 3 software [43] as follows: forward 5'-ATT ATG AGG AGA ATT TAC CTT TCC C-3' for COX-2 .926; reverse 5'-ACT TCA CTA TGA TGA TAT GGT AAT T-3' for COX-2 .5209; and reverse 5'-ATT TTT CTG TCA TCA AAC AAA AAC A-3' for COX-2 .8473. The three allele-specific dye terminators used for each of the three SNPs were $G / C, C / A$ and $G / A$, respectively. The assay was validated by sequencing individuals with all three genotypes, and these known samples were used as positive controls on each plate.

The laboratory staff was blind to the case/control status of individuals. Based on 272 duplicated quality control samples randomly included in genotyping, an estimated error rate of $0.6 \%(5 / 816)$ was observed. Genotyping data were available for $1,067(96.8 \%)$ cases and $1,110(97.3 \%)$ controls who donated blood, which represent $70.8 \%(1,067 / 1,508)$ of eligible cases and $71.3 \%(1,110 / 1,556)$ of eligible controls.

\section{Questionnaire data}

As part of the interviewer-administered main questionnaire, women were asked to report their intake of aspirin, ibuprofen, and acetaminophen. For 1,028 (96.3\%) cases and 1,029 $(92.7 \%)$ controls, both questionnaire data and DNA for genotyping were available. As previously described [5], 'ever use' was defined as taking aspirin, ibuprofen, and/or acetaminophen at least once a week for 6 months or longer. Ever use of any one of these drugs was defined as 'ever NSAID user'. Other factors considered to be potential confounders (see below) were also assessed as part of the in-person interview [36].

\section{Statistical analysis}

Hardy-Weinberg equilibrium was tested to compare the observed and expected genotype frequencies among cases and controls, respectively [44]. Bivariate analyses were conducted to compare distributions of covariates among cases and controls. Unconditional logistic regression with SAS version 9.0 (SAS Institute, Inc., Cary, NC, USA) was used to estimate odds ratios (ORs) and corresponding 95\% confidence intervals (Cls), adjusting for potential confounding factors [45]. The potential confounding variables were assessed individually by comparing the log likelihood ratios derived from a model with and without the variable [45]. Factors that changed the OR estimation of the main effects of genotyping by more than $10 \%$ were considered to be potential confounders; however, none of the covariates considered fulfilled this criterion. Variables found not to confound the associations of interest included the following: age at menarche, parity, lactation, months of lactation, age at first birth, number of miscarriages, history of fertility problems, alcohol drinking, race, education, religion, and marital status. All models were therefore adjusted only for the frequency matching factor age at reference, by 5year age group (defined as age at diagnosis for cases and age at identification for controls).

Haplotype and diplotype frequencies were estimated from genotype data by PHASE version 2.1.1 [46,47], based on Bayesian algorithm. Haplotypes and diplotypes were selected according to the corresponding occurring probabilities with a higher likelihood (with $>0.95$ as the cut-point) [46,47]. The distribution of haplotypes in the cases and controls was compared by $\chi^{2}$ test [48]. The most common haplotype GTT was selected as the reference in the analysis. The risk for breast cancer was estimated for each diplotype compared with the reference (GTT/GTT), with adjustment for age at reference. Diplotypes were treated as categorical variables and were incorporated as dummy variables in the logistic regression models.

Gene-environment interactions were tested by evaluating departures from multiplicative interaction models by including main effect variables and multiplicative interaction terms in the logistic regression model with Wald statistic [45]. Because of our prior data on the effects of NSAIDs by hormone receptor status, polytomous logistic regression was used to estimate the ORs for breast cancer, with the cases categorized by joint hormone receptor status (ER and PR) of the tumor [45].

\section{Results}

The distributions of COX-2 .5209 and COX-2 .8473 genotypes were compatible with those expected from Hardy-Weinberg equilibrium, and the frequencies of the variant $\mathrm{G}$ and $\mathrm{C}$ alleles were respectively $20.0 \%$ and $34.1 \%$. The genotype distribution for COX-2 .926 significantly deviated from HardyWeinberg equilibrium in both controls and combined cases and controls (both $P$ values below 0.003).

No main effects on reduced breast cancer risk were found for the three COX-2 SNPs, even when women were categorized by menopausal status (Table 1 ). The frequency of carrying at least one variant allele ( $C$ allele in $C O X-2.926, G$ allele in COX-2 .5209, or $C$ allele in COX-2 .8473) did not differ significantly from the controls, even when breast cancer groups 
were stratified based on hormone receptor status (data not shown).

Haplotypes and diplotypes for the three COX-2 SNPs reconstructed using PHASE software [46] resulted in eight distinct haplotypes and 18 diplotypes. Five haplotypes and eight diplotypes were sufficiently frequent to calculate ORs (Table 2). The three common haplotypes (GTT, CGC, and GTC) accounted for more than $94.7 \%$ of the alleles. None of the haplotypes exhibited an association with breast cancer risk in this population. The three most frequent diplotypes were GTT/ GTT, GTT/CGC, and GTT/GTC. Compared with the most prevalent reference diplotype (GTT/GTT), an uncommon diplotype (GTT/GGC) was associated with a 50\% decreased risk for breast cancer (adjusted $\mathrm{OR}=0.5,95 \% \mathrm{Cl}=0.2$ to 0.9). The OR remained unchanged when the diplotype was compared with all other diplotype combinations. However, this result is based on very small numbers of individuals. No strong associations were observed between other diplotypes and breast cancer risk.

An inverse association between ever use of aspirin and breast cancer risk was previously reported in this population [5], and a similar result was observed when the analyses were restricted to women who donated blood $(\mathrm{OR}=0.80,95 \% \mathrm{Cl}$ $=0.65$ to 0.98). When we evaluated the associations between ever use of aspirin and breast cancer risk stratified by COX-2 genotype, the decreased OR observed among ever users of aspirin who carried at least one variant $\mathrm{C}$ allele of $\mathrm{COX}-2$ $.8473(\mathrm{OR}=0.7,95 \% \mathrm{Cl}=0.5$ to 0.9$)$ compared with nonusers carrying the wild-type TT genotype (Table 3 ) was similar to the overall OR obtained from ever users of aspirin. No significant interaction was observed ( $P$ for interaction $=0.77$ ). When restricted to hormone receptor positive cases, the reduction in breast cancer risk was slightly stronger for carriers of at least one variant $\mathrm{C}$ allele of COX-2 .8473 who ever used aspirin ( $\mathrm{OR}=0.6,95 \% \mathrm{Cl}=0.4$ to 0.9 ; Table 4 ), although the modest heterogeneity in the ORs was not statistically significant. However, there was significant heterogeneity in the ORs for the interaction between ever NSAID use (including both aspirin and nonaspirin NSAID use) and carrying variant $\mathrm{C}$ allele of $\mathrm{COX}-2.8473(\mathrm{OR}=0.7,95 \% \mathrm{Cl}=0.5$ to $1.0 ; P$ for interaction $=0.02$ ). No significant interaction between ever use of aspirin, ever use of NSAIDs, and variant C allele of COX-2 .8473 was observed in ER/PR-negative breast cancer (Table 4).

When analyzed at the diplotype level, the ORs of ever use of any NSAID alone and carrying the GTT/GGC diplotype alone were, respectively, $0.9(95 \% \mathrm{Cl}=0.8$ to 1.1$)$ and $0.6(95 \% \mathrm{Cl}$ $=0.2$ to 1.4 ) compared with nonusers carrying all other diplotypes (data not shown). Ever use of any NSAID was associated with a pronounced reduction in OR among women carrying the diplotype of GTT/GGC (OR $=0.3,95 \% \mathrm{Cl}=0.1$ to 0.9 ) compared with nonusers with all other diplotypes, but numbers were small in these groups and no significant interaction was observed (data not shown).

\section{Discussion}

The COX-2 pathway is now recognized to be important in human cancer development and progression [49]. Numerous studies have suggested a role for COX-2 in the initiation, promotion, and progression of cancers in different organs [5052]. However, little is known about the role of sequence variation within COX-2 in breast cancer, and modification with NSAID use [32-35]. In the present study, no overall associations between the three studied COX-2 variant alleles and breast cancer risk were found. This finding is consistent with an observation from a nested case-control study conducted in Danish women (361 breast cancer cases and 361 matched controls) [35], but it is not consistent with a report that indicated that the homozygous COX-2 . 8473-CC genotype was associated with breast cancer risk (OR $=2.1,95 \% \mathrm{Cl}=1.3$ to 3.3) in an Austrian population ( 500 cases and 500 controls) [33]. The frequencies of variant CT and CC genotypes in our cases were similar to those in the prior studies $[33,35]$. We found little evidence to suggest that intake of aspirin or ever NSAID use interacted with COX-2 genotypes to affect overall breast cancer risk. However, among women with hormone receptor positive breast cancer, there was some evidence to suggest that the reduction in risk associated with ever NSAID use (including both aspirin and nonaspirin NSAID use) was limited to women who carried the variant $\mathrm{C}$ allele for COX-2 .8473; however, there was no corresponding interaction between this polymorphism and ever aspirin use alone in this subgroup.

Several previous studies, including the SNP500 database [53], have reported the frequency of $C O X-2.8473$ variant $C$ allele in the $3^{\prime}$-UTR in Caucasian populations to range between $31.4 \%$ and $46.5 \%$ [19-21], which is consistent with our finding (34.1\%). Our larger sample size results in a more stable genotyping frequency compared with prior small studies. Although a small previous study [20] found that carriers of the COX-2 .8473 variant $\mathrm{C}$ allele had a significantly increased risk for lung cancer (ORs 2.12 for CT genotype and 4.28 for CC genotype), an expanded study in the same population [28] failed to reproduce the association (ORs 0.96 for CT genotype and 0.97 for CC genotype). Furthermore, the significantly reduced OR observed for the GTT/GGC diplotype (OR $=0.5$, $95 \% \mathrm{Cl}=0.2$ to 0.9 ) in the present study is probably a falsepositive finding caused by chance because of the small number of observations (34 carriers of the diplotype with NSAID data).

Our findings on the roles of COX-2 .8473 polymorphism and NSAIDs among women with hormone receptor positive breast cancer are biologically plausible. Polymorphisms present in the regulatory $3^{\prime}$-UTR of COX-2 might hinder the binding of RNA-binding proteins and modulate mRNA stability and deg- 
Table 1

COX-2 genotypes and risk for breast cancer by menopausal status: Long Island Breast Cancer Study Project, 1996 to 1997

\begin{tabular}{|c|c|c|c|c|}
\hline Genotypes & Cases $(n)^{\mathrm{a}}$ & Controls $(n)^{\mathrm{a}}$ & Crude OR $(95 \% \mathrm{Cl})$ & Adjusted OR $(95 \% \mathrm{Cl})^{\mathrm{b}}$ \\
\hline \multicolumn{5}{|l|}{ All women } \\
\hline \multicolumn{5}{|c|}{ COX-2 .926 (rs20417) } \\
\hline GG & 670 & 691 & 1.0 (ref.) & 1.0 (ref.) \\
\hline $\mathrm{GC}+\mathrm{CC}$ & 387 & 414 & $1.0(0.8-1.1)$ & $1.0(0.8-1.2)$ \\
\hline \multicolumn{5}{|l|}{$\begin{array}{l}\text { COX-2.5209 } \\
\text { (rs20432) }\end{array}$} \\
\hline $\mathrm{TT}$ & 685 & 694 & 1.0 (ref.) & 1.0 (ref.) \\
\hline $\mathrm{TG}+\mathrm{GG}$ & 372 & 399 & $0.9(0.8-1.1)$ & $0.9(0.8-1.1)$ \\
\hline \multicolumn{5}{|c|}{ COX-2 .8473 (rs5275) } \\
\hline $\mathrm{TT}$ & 475 & 467 & 1.0 (ref.) & 1.0 (ref.) \\
\hline $\mathrm{TC}+\mathrm{CC}$ & 585 & 635 & $0.9(0.8-1.1)$ & $0.9(0.8-1.1)$ \\
\hline \multicolumn{5}{|c|}{ Premenopausal women } \\
\hline \multicolumn{5}{|c|}{ COX-2 .926 (rs20417) } \\
\hline GG & 217 & 234 & 1.0 (ref.) & 1.0 (ref.) \\
\hline $\mathrm{GC}+\mathrm{CC}$ & 124 & 142 & $0.9(0.7-1.3)$ & $1.0(0.7-1.4)$ \\
\hline \multicolumn{5}{|l|}{$\begin{array}{l}\text { COX-2 .5209 } \\
\text { (rs20432) }\end{array}$} \\
\hline $\mathrm{TT}$ & 225 & 229 & 1.0 (ref.) & 1.0 (ref.) \\
\hline $\mathrm{TG}+\mathrm{GG}$ & 116 & 142 & $0.8(0.6-1.1)$ & $0.9(0.6-1.2)$ \\
\hline \multicolumn{5}{|c|}{ COX-2 .8473 (rs5275) } \\
\hline TT & 148 & 153 & 1.0 (ref.) & 1.0 (ref.) \\
\hline $\mathrm{TC}+\mathrm{CC}$ & 193 & 223 & $0.9(0.7-1.2)$ & $0.9(0.7-1.2)$ \\
\hline \multicolumn{5}{|c|}{ Postmenopausal women } \\
\hline \multicolumn{5}{|c|}{ COX-2 .926 (rs20417) } \\
\hline GG & 438 & 428 & 1.0 (ref.) & 1.0 (ref.) \\
\hline $\mathrm{GC}+\mathrm{CC}$ & 253 & 255 & $1.0(0.8-1.2)$ & $1.0(0.8-1.2)$ \\
\hline \multicolumn{5}{|l|}{$\begin{array}{l}\text { COX-2.5209 } \\
\text { (rs20432) }\end{array}$} \\
\hline TT & 445 & 438 & 1.0 (ref.) & 1.0 (ref.) \\
\hline $\mathrm{TG}+\mathrm{GG}$ & 246 & 238 & $1.0(0.8-1.3)$ & $1.0(0.8-1.3)$ \\
\hline \multicolumn{5}{|c|}{ COX-2 .8473 (rs5275) } \\
\hline $\mathrm{TT}$ & 318 & 295 & 1.0 (ref.) & 1.0 (ref.) \\
\hline $\mathrm{TC}+\mathrm{CC}$ & 376 & 385 & $0.9(0.7-1.1)$ & $0.9(0.7-1.1)$ \\
\hline
\end{tabular}

an values for cases and controls among all women are not equal to the sum of premenopausal and postmenopausal women because of missing data for menopausal status. ${ }^{b}$ Adjusted for age at reference. Cl, confidence interval; OR, odds ratio.

radation, and finally decrease the production of protein [5456]. Therefore, it is reasonable to speculate that the COX-2 .8473 polymorphism, located downstream of the stop codon in the adenylate/uridylate-rich 3'-UTR region [20], could partly decrease mRNA stability and expression either by modifying the efficiency of polyadenylation signals or by affecting the binding affinity of regulatory elements. This could result in decreased cellular COX-2 activity and reduced inflammatory response, angiogenesis, and tumor growth. Continuous use of any NSAIDs appears to result, via a local blockade of the COX-2 enzyme, in a reduction in $\mathrm{PGE}_{2}$ and aromatase synthesis. The consequent reduction in the local production of estrogen, in turn, is associated with the reduced breast cancer risk $[10-13,57,58]$. However, the fact that there is no direct labo- 
Table 2

COX-2 haplotype and risk for breast cancer: Long Island Breast Cancer Study Project, 1996 to 1997

\begin{tabular}{|c|c|c|c|c|}
\hline $\begin{array}{l}\text { COX-2 haplotype/ } \\
\text { diplotype status }\end{array}$ & Cases $(n)$ & Controls $(n)$ & Adjusted OR $(95 \% \mathrm{Cl})^{\mathrm{a}}$ & $P$ value \\
\hline \multicolumn{5}{|l|}{ Haplotype ${ }^{b}$} \\
\hline GTT & 1,359 & 1,405 & 1.0 (ref.) & \\
\hline CGC & 363 & 388 & $1.0(0.8-1.2)$ & 0.85 \\
\hline GTC & 299 & 306 & $1.0(0.8-1.2)$ & 0.95 \\
\hline GGC & 38 & 60 & $0.7(0.5-1.0)$ & 0.06 \\
\hline CTT & 27 & 33 & $0.8(0.5-1.4)$ & 0.48 \\
\hline \multicolumn{5}{|c|}{ Diplotype (haplotype pairs) } \\
\hline GTT GTT & 434 & 432 & 1.0 (ref.) & \\
\hline GTT CGC & 239 & 262 & $0.9(0.7-1.1)$ & 0.45 \\
\hline GTT GTC & 186 & 194 & $1.0(0.7-1.2)$ & 0.69 \\
\hline GTC CGC & 49 & 51 & $0.9(0.6-1.4)$ & 0.79 \\
\hline GTC GTC & 26 & 25 & $1.0(0.6-1.8)$ & 0.94 \\
\hline GTT GGC & 12 & 27 & $0.5(0.2-0.9)^{c}$ & 0.03 \\
\hline GTT CTT & 19 & 24 & $0.7(0.4-1.4)$ & 0.36 \\
\hline CGC CGC & 25 & 23 & $1.1(0.6-2.1)$ & 0.68 \\
\hline Others & 47 & 36 & $1.3(0.8-2.0)$ & 0.31 \\
\hline
\end{tabular}

${ }^{a}$ Adjusted for age at reference. ${ }^{b} \mathrm{COX}-2$ haplotype composed of three polymorphic sites: COX-2.926 G $\rightarrow \mathrm{C}, \mathrm{COX}-2.5209 \mathrm{~T} \rightarrow \mathrm{G}$, and COX-

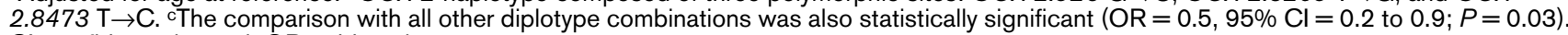

$\mathrm{Cl}$, confidence interval; OR, odds ratio.

ratory evidence on the function of the COX-2 .8473 polymorphism may increase the likelihood of a spurious association or indicate the presence of some other functional SNPs in strong linkage disequilibrium with this SNP.

The more pronounced interaction between the COX-2 .8473 polymorphism and ever NSAID use in ER-positive or PR-positive tumors than that in ER/PR-negative tumors is of particular interest. This might be an indication that different mechanisms are involved in subtypes of breast cancer. The lower frequency of COX-2 over-expression in hormone receptor positive tumors may make it easier to observe a significant protective effect of NSAID use among carriers of the variant $C$ allele of COX-2 .8473. This is consistent with the observation that elevated expression of COX-2 was statistically significantly associated with poor survival in ER-positive or PR-positive tumors but not in ER/PR-negative ones [14]. The same dose of NSAIDs might have a protective effect in ER-positive or PRpositive tumors by acting on an inflammation-related pathway through decreasing COX-2 activity, reducing $\mathrm{PGE}_{2}$ and aromatase synthesis, and decreasing estrogen production. However, there are also several discrepant reports showing that long-term daily use of aspirin significantly increased risk for ER/PR-negative breast cancer [7], and ER-negative tumors are more sensitive to chemotherapy than are ER-positive ones [59]. We did not observe a significant interaction between ever aspirin use, ever NSAID use, and the variant $C$ allele of COX-2 .8473 in ER/PR-negative breast cancer, perhaps because of limited power (Table 4). The nonsignificant interaction observed in ever aspirin use might be a reflection of either inadequate power or lack of a true association. Considering the biologic mechanism of action of aspirin and nonaspirin NSAIDs and the results obtained in the present study (Table 4), we believe that this inconsistency is due to limited power resulting from the small sample size in some subgroups of aspirin users. The observed significant interaction between ever NSAID use and the variant $C$ allele of COX-2 .8473 for decreasing breast cancer risk also included, to a certain extent, a contribution of ever aspirin use. The ORs for interactions between the genotype and either ever aspirin use or ever NSAID use were essentially similar (OR $0.6,95 \% \mathrm{Cl}=0.4$ to 0.9 versus $0.7,95 \% \mathrm{Cl}=0.5$ to 1.0 ). This is consistent with the results from our analysis of the interactions between nonaspirin NSAID use alone, aspirin use alone, and COX-2 .8473 polymorphism (data not shown). Thus, the difference in interaction between ever aspirin use, ever NSAID use, and the COX-2 .8473 polymorphism might well be the result of limited 
COX-2 genotypes, NSAIDs use, and risk for breast cancer: Long Island Breast Cancer Study Project, 1996 to 1997

\begin{tabular}{|c|c|c|c|c|}
\hline & \multicolumn{2}{|c|}{ No use } & \multicolumn{2}{|c|}{ Ever use } \\
\hline & Cases/controls & OR $(95 \% \mathrm{Cl})^{\mathrm{a}}$ & Cases/controls & OR $(95 \% \mathrm{Cl})^{a}$ \\
\hline \multicolumn{5}{|l|}{ Aspirin } \\
\hline \multicolumn{5}{|c|}{ COX-2 .926 (rs20417) } \\
\hline GG & $511 / 484$ & 1.0 (ref.) & $138 / 156$ & $0.8(0.6-1.0)$ \\
\hline $\mathrm{GC}+\mathrm{CC}$ & $285 / 291$ & $0.9(0.8-1.1)$ & $84 / 93$ & $0.8(0.6-1.1)$ \\
\hline \multicolumn{5}{|c|}{ COX-2 .5209 (rs20432) } \\
\hline $\mathrm{TT}$ & $521 / 485$ & 1.0 (ref.) & $145 / 160$ & $0.8(0.6-1.0)$ \\
\hline $\mathrm{TG}+\mathrm{GG}$ & $275 / 282$ & $0.9(0.7-1.1)$ & $78 / 86$ & $0.8(0.6-1.1)$ \\
\hline \multicolumn{5}{|c|}{ COX-2 .8473 (rs5275) } \\
\hline TT & 363/332 & 1.0 (ref.) & $98 / 101$ & $0.8(0.6-1.1)$ \\
\hline $\mathrm{TC}+\mathrm{CC}$ & $436 / 439$ & $0.9(0.8-1.1)$ & $124 / 148$ & $0.7(0.5-0.9)^{\mathrm{b}}$ \\
\hline \multicolumn{5}{|l|}{ Any NSAID } \\
\hline \multicolumn{5}{|c|}{ COX-2 .926 (rs20417) } \\
\hline GG & $418 / 412$ & 1.0 (ref.) & $235 / 240$ & $0.9(0.7-1.1)$ \\
\hline $\mathrm{GC}+\mathrm{CC}$ & $245 / 249$ & $0.9(0.8-1.2)$ & $126 / 137$ & $0.8(0.6-1.1)$ \\
\hline \multicolumn{5}{|c|}{ COX-2 .5209 (rs20432) } \\
\hline $\mathrm{TT}$ & $427 / 417$ & 1.0 (ref.) & $243 / 240$ & $0.9(0.7-1.1)$ \\
\hline $\mathrm{TG}+\mathrm{GG}$ & $237 / 237$ & $1.0(0.8-1.2)$ & $118 / 133$ & $0.8(0.6-1.1)$ \\
\hline \multicolumn{5}{|c|}{ COX-2 .8473 (rs5275) } \\
\hline $\mathrm{TT}$ & $290 / 285$ & 1.0 (ref.) & $175 / 155$ & $1.1(0.8-1.4)$ \\
\hline $\mathrm{TC}+\mathrm{CC}$ & $376 / 371$ & $1.0(0.8-1.3)$ & $186 / 223$ & $0.8(0.6-1.0)$ \\
\hline
\end{tabular}

aAdjusted for age at reference. bMultiplicative interaction term was not significant $(P$ for interaction $=0.69)$, by Wald statistic. $\mathrm{Cl}$, confidence interval; OR, odds ratio.

power for subgroup analyses rather than lack of a true association.

The relatively large sample size, population-based study design, and availability of both genotyping and NSAID information are the strengths of the study. The NSAID data were obtained from retrospective reporting of medication use, which might lead to recall bias. However, in order to explain our findings, cases should under-report more than controls or the accuracy of reporting should be related to genotype status or ER/PR status. Thus, it is unlikely that recall bias played a major role in explaining the present findings. Previous sensitivity analysis also indicated that the missing data would not have altered the overall conclusion of a protective effect between aspirin use and breast cancer [5].

Another consideration was that our NSAIDs information did not include the use of prescription drugs containing NSAIDs (such as naproxen, etodolac, ketoprofen, and sulindac). The presumed 'unexposed' women who used prescription NSAIDs would be included in the nonuser category and lead to an underestimation of inverse associations. Such a misclassification of users as nonusers would tend to bias estimates of NSAID effects toward the null. The extensive information collected in the study for evaluating confounding factors and effect modifiers allowed us to assess confounding in the data analysis. ORs changed less than $10 \%$ when considering potential confounding factors individually or in multivariate models, indicating that the effects of confounding are limited. Inclusion of age at reference in logistic models minimized any possible residual confounding effect of age. Although our questionnaire also included variables on duration and frequency of aspirin and other NSAID use, providing some information on dose, the small sample size in some subgroups when categorized by COX-2 genotype limited power to evaluate dose-response effects.

\section{Conclusion}

This population-based case-control study provided some evidence to support our hypothesis that the COX-2.8473 variant 
Table 4

COX-2 2473 genotype, NSAIDs use, and risk for breast cancer by hormone receptor status, Long Island Breast Cancer Study Project, 1996-1997

\begin{tabular}{|c|c|c|c|c|c|}
\hline \multirow{2}{*}{$\begin{array}{l}\text { COX-2 .8473 } \\
\text { genotype }\end{array}$} & \multirow[t]{2}{*}{ Aspirin/any NSAID } & \multicolumn{2}{|c|}{ No use } & \multicolumn{2}{|c|}{ Ever use } \\
\hline & & Cases/controls & OR $(95 \% \mathrm{Cl})^{\mathrm{a}}$ & Cases/controls & OR $(95 \% \mathrm{Cl})^{\mathrm{a}}$ \\
\hline \multicolumn{6}{|l|}{ ER or PR positive } \\
\hline TT & Aspirin & 191/332 & 1.0 (ref.) & $46 / 101$ & $0.7(0.5-1.0)$ \\
\hline $\mathrm{TC}+\mathrm{CC}$ & & $237 / 439$ & $1.0(0.7-1.2)$ & $61 / 148$ & $0.6(0.4-0.9)^{\mathrm{b}}$ \\
\hline $\mathrm{TT}$ & Any NSAID & $147 / 285$ & 1.0 (ref.) & $92 / 155$ & $1.1(0.8-1.5)$ \\
\hline $\mathrm{TC}+\mathrm{CC}$ & & $210 / 371$ & $1.1(0.9-1.5)$ & $89 / 223$ & $0.7(0.5-1.0)^{\mathrm{c}}$ \\
\hline \multicolumn{6}{|c|}{ ER and PR negative } \\
\hline $\mathrm{TT}$ & Aspirin & $44 / 332$ & 1.0 (ref.) & $13 / 101$ & $1.0(0.5-1.8)$ \\
\hline $\mathrm{TC}+\mathrm{CC}$ & & $53 / 439$ & $0.9(0.6-1.4)$ & $22 / 148$ & $1.1(0.6-1.9) d$ \\
\hline $\mathrm{TT}$ & Any NSAID & $40 / 285$ & 1.0 (ref.) & $18 / 155$ & $0.8(0.5-1.5)$ \\
\hline $\mathrm{TC}+\mathrm{CC}$ & & $39 / 371$ & $0.8(0.5-1.2)$ & $37 / 223$ & $1.2(0.7-1.9)^{\mathrm{e}}$ \\
\hline
\end{tabular}

aAdjusted for age at reference. bMultiplicative interaction term was not significant $(P$ for interaction $=0.78)$ by Wald statistic. ${ }^{c}$ Multiplicative interaction term was significant $(P$ for interaction $=0.02)$ by Wald statistic. dMultiplicative interaction term was not significant $(P$ for interaction $=$ 0.59 ) by Wald statistic. eMultiplicative interaction term was not significant $(P$ for interaction $=0.10)$ by Wald statistic. $\mathrm{Cl}$, confidence interval; ER, estrogen receptor; NSAID, nonsteroidal anti-inflammatory drug; OR, odds ratio; PR, progesteron receptor.

C allele may be a genetic modifier for ever use of NSAIDs and reduced breast cancer risk among hormone receptor positive cases, but we observed no corresponding interaction with aspirin use alone, which may be due to reduced power in this subgroup. Because there has been no laboratory evaluation of the biologic function of COX-2.8473 polymorphism, additional studies to examine the functionality of the polymorphism and the potential interactions with various inflammation-related genes are warranted.

\section{Competing interests}

The authors declare that they have no competing interests.

\section{Authors' contributions}

JS was responsible for genotyping polymorphisms, data analyses and interpretation, and drafting of the manuscript. MG contributed to study design, sample collection and manuscript preparation, and provided expertise in data analyses. MBT, SL, and $\mathrm{AN}$ contributed to the study design, sample collection, and manuscript preparation. RS was responsible for supervising laboratory work, and contributed to study design, biospecimen processing and manuscript preparation. All authors read and approved the final manuscript.

\section{Acknowledgements}

Funded by grants U01 CA/ES66572, P30ES09089, and

P3OES10126 from the National Cancer Institute and the National Institute of Environmental Health Sciences, an award from the Breast Cancer Research Foundation, and gifts from private citizens.

\section{References}

1. Khuder SA, Mutgi AB: Breast cancer and NSAID use: a metaanalysis. Br J Cancer 2001, 84:1188-1192.

2. Harris RE, Kasbari S, Farrar WB: Prospective study of nonsteroidal anti-inflammatory drugs and breast cancer. Oncol Rep 1999, 6:71-73.

3. Garcia Rodriguez LA, Gonzalez-Perez A: Risk of breast cancer among users of aspirin and other anti-inflammatory drugs. $\mathrm{Br}$ $J$ Cancer 2004, 91:525-529.

4. Moorman PG, Grubber JM, Millikan RC, Newman B: Association between non-steroidal anti-inflammatory drugs (NSAIDs) and invasive breast cancer and carcinoma in situ of the breast. Cancer Causes Control 2003, 14:915-922.

5. Terry MB, Gammon MD, Zhang FF, Tawfik H, Teitelbaum SL, Britton JA, Subbaramaiah K, Dannenberg AJ, Neugut Al: Association of frequency and duration of aspirin use and hormone receptor status with breast cancer risk. JAMA 2004, 291:2433-2440.

6. Jacobs EJ, Thun MJ, Connell CJ, Rodriguez C, Henley SJ, Feigelson HS, Patel AV, Flanders WD, Calle EE: Aspirin and other nonsteroidal anti-inflammatory drugs and breast cancer incidence in a large U.S. cohort. Cancer Epidemiol Biomarkers Prev 2005, 14:261-264.

7. Marshall SF, Bernstein L, Anton-Culver H, Deapen D, Horn-Ross PL, Mohrenweiser H, Peel D, Pinder R, Purdie DM, Reynolds P, et al:: Nonsteroidal anti-inflammatory drug use and breast cancer risk by stage and hormone receptor status. J Nat/ Cancer Inst 2005, 97:805-812.

8. Dixon DA: Dysregulated post-transcriptional control of COX-2 gene expression in cancer. Curr Pharm Des 2004, 10:635-646.

9. Hwang D, Scollard D, Byrne J, Levine E: Expression of cyclooxygenase-1 and cyclooxygenase-2 in human breast cancer. $J$ Natl Cancer Inst 1998, 90:455-460.

10. Pereg $D$, Lishner M: Non-steroidal anti-inflammatory drugs for the prevention and treatment of cancer. J Intern Med 2005, 258:115-123.

11. Brodie AM, Lu Q, Long BJ, Fulton A, Chen T, Macpherson N, DeJong PC, Blankenstein MA, Nortier JW, Slee PH, et al.: Aromatase and COX-2 expression in human breast cancers. $J$ Steroid Biochem Mol Biol 2001, 79:41-47.

12. Elvin JA, Yan $C$, Matzuk MM: Growth differentiation factor-9 stimulates progesterone synthesis in granulosa cells via a 
prostaglandin E2/EP2 receptor pathway. Proc Natl Acad Sci USA 2000, 97:10288-10293.

13. Arun B, Goss P: The role of COX-2 inhibition in breast cancer treatment and prevention. Semin Oncol 2004, 31:22-29.

14. Ristimaki A, Sivula A, Lundin J, Lundin M, Salminen T, Haglund C, Joensuu $\mathrm{H}$, Isola J: Prognostic significance of elevated cyclooxygenase-2 expression in breast cancer. Cancer Res 2002, 62:632-635

15. Papafili A, Hill MR, Brull DJ, McAnulty RJ, Marshall RP, Humphries $\mathrm{SE}$, Laurent GJ: Common promoter variant in cyclooxygenase2 represses gene expression: evidence of role in acute-phase inflammatory response. Arterioscler Thromb Vasc Biol 2002, 22:1631-1636.

16. Cipollone $F$, Toniato $E$, Martinotti S, Fazia M, lezzi A, Cuccurullo $C$, Pini B, Ursi S, Vitullo G, Averna M, et al.: A polymorphism in the cyclooxygenase 2 gene as an inherited protective factor against myocardial infarction and stroke. JAMA 2004, 291:2221-2228

17. Zhang X, Miao X, Tan W, Ning B, Liu Z, Hong Y, Song W, Guo Y, Zhang $X$, Shen $Y$, et al:: Identification of functional genetic variants in cyclooxygenase-2 and their association with risk of esophageal cancer. Gastroenterology 2005, 129:565-576.

18. Brosens LA, lacobuzio-Donahue CA, Keller JJ, Hustinx SR, Carvalho R, Morsink FH, Hylind LM, Offerhaus GJ, Giardiello FM, Goggins $\mathrm{M}$ : Increased cyclooxygenase-2 expression in duodenal compared with colonic tissues in familial adenomatous polyposis and relationship to the -765G $\rightarrow$ C COX-2 polymorphism. Clin Cancer Res 2005, 11:4090-4096.

19. Ali IU, Luke BT, Dean M, Greenwald P: Allellic variants in regulatory regions of cyclooxygenase-2: association with advanced colorectal adenoma. Br J Cancer 2005, 93:953-959.

20. Campa D, Zienolddiny S, Maggini V, Skaug V, Haugen A, Canzian $\mathrm{F}$ : Association of a common polymorphism in the cyclooxygenase $\mathbf{2}$ gene with risk of non-small cell lung cancer. Carcinogenesis 2004, 25:229-235.

21. Cox DG, Pontes C, Guino E, Navarro M, Osorio A, Canzian F, Moreno V, Bellvitge Colorectal Cancer Study Group: Polymorphisms in prostaglandin synthase 2/cyclooxygenase 2 (PTGS2/COX2) and risk of colorectal cancer. Br J Cancer 2004, 91:339-343.

22. Hu Z, Miao X, Ma H, Wang X, Tan W, Wei Q, Lin D, Shen H: A common polymorphism in the 3'UTR of cyclooxygenase 2/ prostaglandin synthase 2 gene and risk of lung cancer in a Chinese population. Lung Cancer 2005, 48:11-17.

23. Koh WP, Yuan JM, va den Berg D, Lee HP, Yu MC: Interaction between cyclooxygenase-2 gene polymorphism and dietary $n-$ 6 polyunsaturated fatty acids on colon cancer risk: the Singapore Chinese Health Study. Br J Cancer 2004, 90:1760-1764.

24. Panguluri RC, Long LO, Chen W, Wang S, Coulibaly A, Ukoli F, Jackson A, Weinrich S, Ahaghotu C, Isaacs W, Kittler RA: COX-2 gene promoter haplotypes and prostate cancer risk. Carcinogenesis 2004, 25:961-966

25. Siezen CL, van Leeuwen Al, Kram NR, Luken ME, van Kranen HJ, Kampman E: Colorectal adenoma risk is modified by the interplay between polymorphisms in arachidonic acid pathway genes and fish consumption. Carcinogenesis 2005, 26:449-457.

26. Ulrich CM, Whitton J, Yu JH, Sibert J, Sparks R, Potter JD, Bigler $J$ : PTGS2 (COX-2) -765G >C promoter variant reduces risk of colorectal adenoma among nonusers of nonsteroidal antiinflammatory drugs. Cancer Epidemiol Biomarkers Prev 2005, 14:616-619.

27. Kang S, Kim YB, Kim MH, Yoon KS, Kim JW, Park NH, Song YS, Kang D, Yoo KY, Kang SB, Lee HP: Polymorphism in the nuclear factor kappa-B binding promoter region of cyclooxygenase-2 is associated with an increased risk of bladder cancer. Cancer Lett 2005, 217:11-16.

28. Campa D, Hung RJ, Mates D, Zaridze D, Szeszenia-Dabrowska N, Rudnai P, Lissowska J, Fabianova E, Bencko V, Foretova L, et al.: Lack of association between polymorphisms in inflammatory genes and lung cancer risk. Cancer Epidemiol Biomarkers Prev 2005, 14:538-539.

29. Park JM, Choi JE Chae MH, Lee WK Cha SI, Son JW, Kim CH, Kam S, Kang YM, Jung TH, Park JY: Relationship between cyclooxygenase 8473T $>C$ polymorphism and the risk of lung cancer: a case-control study. BMC Cancer 2006, 6:70.
30. Sakoda LC, Gao YT, Chen BE, Chen J, Rosenberg PS, Rashid A Deng J, Shen MC, Wang BS, Han TQ, et al:: Prostaglandinendoperoxide synthase 2 (PTGS2) gene polymorphisms and risk of biliary tract cancer and gallstones: a population-based study in Shanghai, China. Carcinogenesis 2006, 27:1251-1256.

31. Liu F, Pan K, Zhang X, Zhang Y, Zhang L, Ma J, Dong C, Shen L, Li J, Deng D, et al:: Genetic variants in cyclooxygenase-2: expression and risk of gastric cancer and its precursors in a chinese population. Gastroenterology 2006, 130:1975-1984.

32. Moorman PG, Sesay J, Nwosu V, Kane JG, de Cotret AR, Worley $\mathrm{K}$, Millikan R: Cyclooxygenase 2 polymorphism (Val511Ala), nonsteroidal anti-inflammatory drug use and breast cancer in African American women. Cancer Epidemiol Biomarkers Prev 2005, 14:3013-3014.

33. Langsenlehner U, Yazdani-Biuki B, Eder T, Renner W, Wascher TC, Paulweber B, Weitzer W, Samonigg H, Krippl P: The Cyclooxygenase-2 (PTGS2) 8473T $>$ C Polymorphism is Associated with Breast Cancer Risk. Clin Cancer Res 2006, 12:1392-1394.

34. Gallicchio L, McSorley MA, Newschaffer CJ, Thuita LW, Huang HY, Hoffman SC, Helzlsouer KJ: Nonsteroidal antiinflammatory drugs, cyclooxygenase polymorphisms, and the risk of developing breast carcinoma among women with benign breast disease. Cancer 2006, 106:1443-1452.

35. Vogel U, Christensen J, Nexo BA, Wallin $\mathrm{H}$, Friis $\mathrm{S}$, Tjonneland $\mathrm{A}$ : Peroxisome profilerator-activated receptor\{gamma\}2 Pro12Ala, interaction with alcohol intake and NSAID use, in relation to risk of breast cancer in a prospective study of Danes. Carcinogenesis 2006 in press.

36. Gammon MD, Negut Al, Santella RM, Teitelbaum SL, Britton JA Terry MB, Eng SM, Wolff MS, Stellman SD, Kabat GC et al: The Long Island Breast Cancer Study Project: description of a multi-institutional collaboration to identify environmental risk factors for breast cancer. Breast Cancer Res Treat 2002, 74:235-254.

37. Kosaka T, Miyata A, Ihara H, Hara S, Sugimoto T, Takeda O, Takahashi $E$, Tanabe $T$ : Characterization of the human gene (PTGS2) encoding prostaglandin-endoperoxide synthase 2. Eur J Biochem 1994, 221:889-897.

38. dbSNP Homepage [http://www.ncbi.nlm.nih.gov/SNP/]

39. UCSC Genome Bioinformatics [http://genome.ucsc.edu/]

40. GeneCards Homepage [http://genecards.bcgsc.bc.ca/]

41. Gammon MD, Santella RM, Neugut Al, Eng SM, Teitelbaum SL, Paykin A, Levin B, Terry MB, Young TL, Wang LW, et al.: Environemntal toxins and breast cancer on Long Island. I. Polycyclic aromatic hydrocarbon DNA adducts. Cancer Epidemiol Biomarkers Prev 2002, 11:677-685.

42. Chen X, Levine L, Kwok PY: Fluorescence polarization in homogeneous nucleic acid analysis. Genome Res 1999, 9:492-498.

43. Primer3 Homepage [http://frodo.wi.mit.edu/cgi-bin/primer3/ primer3 www.cgil

44. Cox DG, Canzian F: Genotype transposer: automated genotype manipulation for linkage disequilibrium analysis. Bioinformatics 2001, 17:738-739.

45. Hosmer DW, Lemenshow S: Applied Logistic Regression New York: John Wiley \& Sons; 1989.

46. Stephens M, Smith NJ, Donnelly P: A new statistical method for haplotype reconstruction from population data. $\mathrm{Am} J \mathrm{Hum}$ Genet 2001, 68:978-989.

47. Tregouet DA, Escolano S, Tiret L, Mallet A, Golmard JL: A new algorithm for haplotype-based association analysis: the Stochastic-EM algorithm. Ann Hum Genet 2004, 68:165-177.

48. Rothman KJ, Greenland S: Modern Epidmeiology New York: Lippcott-Raven; 1998.

49. Dannenberg AJ, Subbaramaiah K: Targeting cyclooxygenase-2 in human neoplasia: rationale and promise. Cancer Cell 2003 4:431-436.

50. Dannenberg AJ, Altorki NK, Boyle JO, Dang C, Howe LR, Weksler $\mathrm{BB}$, Subbaramaiah K: Cyclo-oxygenase 2: a pharmacological target for the prevention of cancer. Lancet Oncol 2001, 2:544-551.

51. Dannenberg AJ, Howe LR: The role of COX-2 in breast and cervical cancer. Prog Exp Tumor Res 2003, 37:90-106.

52. Herschman HR: Prostaglandin synthase 2. Biochim Biophys Acta 1996, 1299:125-140. 
53. SNP500Cancer Homepage [http://snp500cancer.nci.nih.gov/ home 1.cfm]

54. Di Marco S, Hel Z, Lachance C, Furneaux H, Radzioch D: Polymorphism in the 3 '-untranslated region of TNFalpha mRNA impairs binding of the post-transcriptional regulatory protein HuR to TNFalpha mRNA. Nucleic Acids Res 2001, 29:863-871.

55. Hall-Pogar T, Zhang H, Tian B, Lutz CS: Alternative polyadenylation of cyclooxygenase-2. Nucleic Acids Res 2005, 33:2565-2579.

56. Cok SJ, Acton SJ, Morrison AR: The proximal region of the $3^{\prime}-$ untranslated region of cyclooxygenase- 2 is recognized by a multimeric protein complex containing HuR, TIA-1, TIAR, and the heterogeneous nuclear ribonucleoprotein U. J Biol Chem 2003, 278:36157-36162.

57. Oliveira VM, Piato S, Silva MA: Correlation of cyclooxygenase-2 and aromatase immunohistochemical expression in invasive ductal carcinoma, ductal carcinoma in situ, and adjacent normal epithelium. Breast Cancer Res Treat 2005, 95:235-241.

58. DuBois RN: Aspirin and breast cancer prevention: the estrogen connection. JAMA 2004, 291:2488-2489.

59. Andre F, Pusztai L: Molecular classification of breast cancer: implications for selection of adjuvant chemotherapy. Nat Clin Pract Oncol 2006, 3:621-632. 